\title{
Patriarchal family relationship under threat during forced migration. The case of Burundians in Mahama refugee camp, Rwanda
}

\begin{abstract}
BACKGROUND
Patriarchal structure puts men in a position to rule, control, decide, and provide for the family and the household. However, during forced migration, men's resources and survival capacity are reduced and are dependent on humanitarian donors' decisions. While the literature focuses on migrant men's struggle to cope with life, little is known about how forced migration affects the existing relationships of couples from a patriarchal background. This paper sheds light on this matter using the case of Burundian refugees received in Mahama Camp, Rwanda, since April 2015.
\end{abstract}

\section{PARTICIPANTS AND PROCEDURE}

Twenty-one men chosen through systematic and purposive sampling techniques were included in the study, of whom 10 were interviewed individually and 11 were approached in a focus group discussion (FGD). Five key informants also contributed to this study. This is a qualitative study during which data were collected using semi-structured interview and FGD guides.

\begin{abstract}
RESULTS
The results showed that forced migration brought changes in patriarchal family relationships as well as in traditional gendered roles. Almost all the participants confirmed that in Mahama refugee camp, men were no longer providers for their families and one third specified that men were no longer heads of families. Rather, women found an opportunity to be breadwinners, providers, decision makers, and dominant. This new structure negatively affected the relationships of couples and family security.
\end{abstract}

\section{CONCLUSIONS}

The study suggested the creation of a special family promotion service within the camp, organisation of campaigns on gender equality and positive masculinity, and the establishment of spaces for men and women to work and produce rather than totally depending on the international community.

\section{KEY WORDS}

forced migration; Burundian refugees; Mahama camp; patriarchal family

ORGANIZATION - 1: University of Rwanda, Kigali, Rwanda 2: IntraHealth, Kigali, Rwanda AUthors' Contributions - A: Study design - B: Data collection - C: Statistical analysis - D: Data interpretation .

E: Manuscript preparation · F: Literature search · G: Funds collection

CORRESPONDING AUthor - Innocent lyakaremye, Ph.D., Centre for Gender Studies, University of Rwanda, PO Box: 5039 Kigali, Rwanda, e-mail: iyakin7@gmail.com

TO CITE THIS ARTICLE - Iyakaremye, I., Musabyimana, P., \& Umutoni, J. (2019). Patriarchal family relationship under threat during forced migration. The case of Burundians in Mahama refugee camp, Rwanda. Health Psychology Report,

7(3), 229-241. https://doi.org/10.5114/hpr.2019.88223

RECEIVED 01.03.2019 • REVIEWED 08.09.2019 • ACCEPTED 08.09.2019 • PUBLISHED 25.09.2019 


\section{BACKGROUND}

This paper discusses the influence of forced migration on the family relationship within a patriarchal context with special focus on Burundians hosted in Mahama refugee camp, Rwanda. Male supremacy in patriarchal society is not an unchangeable position. However, a gentle and procedural response is always necessary. Asiyanbola (2005) views patriarchy as a system that provides material benefits to men to the disadvantage of women, where all sorts of social, political and economic discrimination against women are observed. Initially understood as the rule of the father, the concept of patriarchy was extended, especially by feminists, to indicate the power relation between men and women, within which males systematically dominate while females and less powerful males are dominated by men (Sultana, 2011).

Sultana (2011) traces the origin of the concept of patriarchy from the writings of early philosophers and psychologists such as Aristotle, Sigmund Freud, and Friedrich Engels. Sultana (2011) argues that since patriarchy is not natural, it can be changed as well. At this point, Kambarami (2006) suggests the resocialisation of the community through the family institution, laws and policies, as well as intense sensitization.

Males' advantage and domination as well as females' discrimination and subordination as mentioned above are fuelled by the capacity, the power, and the authority invested in men by the culture. However, the conditions of forced migration change patriarchal established structure as well as gender roles, reducing the man's social responsibilities and capacities that previously used to make him feel able, worthy and integrated (Page, 1999). For Del Aguila (2014), migrating men experience internal inconsistency, tensions, and contradictions in relation to their being as men. According to Donaldson and Howson (2009), migrant men are more in need of welfare support than women are, given men's exposure to all kinds of impediments in the foreign land. In addition, as they explain, men always expect to meet manhood at the standard of their culture, wherever they are, which constitutes another kind of barrier and source of frustration if these standards are not reached. The unexpected change resulting from forced, new, and foreign life is therefore unpleasant to men and is likely to create frustration in them and negatively affect their relationship with family members, hence compromising their expected security, stability, and dignity.

Although forced migration and its influence on men's relations with family members has been explored in some parts of the world, it is poorly explored in the context of the Great Lakes region, which has for long experienced and is still experiencing forms of genocide, wars and other conflicts which result in having many people unwillingly leaving their homes and countries in the search of safer places. Currently, the Great Lakes Region is filled with migrant people from a patriarchal background hosted in different places. Burundi, which is located in this region, is a highly patriarchal society (Basse \& Kwizera, 2017). In 2015, 232,881 refugees had fled Burundi to settle in neighbouring countries and abroad, and this number was the second highest in the Great Lakes Regions after the Democratic Republic of Congo (Tunda, 2016). In 2017, Burundian refugees in Mahama camp, Rwanda, where this study was conducted comprised almost half (43.1\%) of all refugees in Rwanda from neighbouring countries.

It was therefore imperative to explore how men from this patriarchal community manage their masculinity and manhood in the midst of frustrating refugee life conditions. Key questions to explore are: Do men's advantages as defined within a patriarchal system remain during forced migration? Do men keep their position as family providers? In which ways does the refugee life affect men's relationship with their female partners and what are the coping mechanisms?

The information generated will allow governments and the international community to strategize accordingly in matters of receiving and attending to refugees. It will also complement existing literature with information previously unknown on this phenomenon. In a nutshell, the study contributes to analysing how forced migration affects the structure and gender roles in patriarchal families and the subsequent risks with regard to family stability, security, power and relationships. This study will make recommendations to various stakeholders in order to better protect the family institution, and to promote gender justice and human rights within refugee camps.

The overall objective of this study is to explore how forced migration affects patriarchal structure and bonding among couples and to suggest strategies to address related challenges while promoting gender justice and protecting the family institution. The study has three specific objectives, namely: to examine the stability of patriarchal family structure and gender role division during forced migration, to discern the influence of family structural dynamics on the couples' power sharing and relations, and to identify coping mechanisms of couples in reaction to the new structural setting of the family. In this regard, the following section on background and literature review helps to frame the scope of this study. The section on methodology shows the steps and procedures followed from the conception up to the writing through collection and analysis of data. Then results are presented and discussed at the same time and concluding remarks provided. 


\section{LITERATURE REVIEW}

The literature highlights a number of types of families and the types of relationships that they develop. Families include married couples, stepfamilies, single-parent families, multigenerational families, cohabiting adults, child-free families, and families headed by gays or lesbians (Nyirahabimana, 2015). However, marriage dominates in the formation of families. The common aspect of all these types is that family members develop and maintain emotional attachment, including intimate intercourse, conception and birth as well as other advantages such as social and economic benefits and protection.

In Western societies, the family institution has been seriously challenged since the 1960s and thus many have opted for cohabitation and divorce rather than formal wedding or remaining together in marriage. In Africa, the family institution is much more valued. The African family also has unique bonding among extended family members such as parents and grandparents, aunts, uncles, etc. (Umoh \& Adeyemi, 1990). These members contribute much to the life of the family in terms of peaceful life development and sometimes in trouble making.

Three steps are followed in most African marriages: "customary marriages officiated according to the traditional rituals, religious marriage celebrated following a given religion's rules, and civil marriage that is contracted based on the civil law of the country" (Strijdom, Luttig, Ferreira, Kellerman, \& Swart, 1997). In the Burundian refugee community under study, these three steps are also followed.

In the framework of this study, the concept of family is considered as "a group of persons related by kinship, law or marriage; it may include parents, children, their descendants and in-laws" (Republic of Rwanda, 2016a, Art. 2.20). As to the concept of couple, its meaning is similar to the one used in demographic censuses and other big surveys. In demographic and health surveys, the concept of "couple" is taken as women and men legally bound together (legally married) as well as women and men cohabiting in informal unions (living together) (Republic of Rwanda, 2016b). These are the kinds of people whose relationship's consistency is analysed in Mahama refugee camp.

Speaking of a refugee camp refers to the issue of migration. This notion is explained in various ways by different individual authors and organisations. Bhugra and Becker (2005) define this concept as "the process of going from one country, region or place of residence to settle in another" (p. 18). While they indicate the intention of migrants as settling, the International Migration Organisation (IMO) instead relates this concept to any population's movement no matter the distance or the duration. They thus explain it as "a process of moving, either across an in- ternational border, or within a State. It is a population movement, encompassing any kind of movement of people, whatever its length, composition and cause" (Bell, Alves, Silveirinha de Oliveira, \& Zuin, 2010).

The literature tries to identify the types of migrations but authors use different frameworks. AP Human Geography (n.d.) uses the reasons behind the migration. They include three reasons - economic, cultural and environmental - and attribute to each one push factors in the origin area and pull factors in the destination area. At the economic level, as they note, people leave their places with the expectation of getting a job, a better job or business in the new places. At the cultural level, they mention the slavery where people have been forcibly taken from their countries to work in overseas countries, and political instability where people leave unsecured locations to settle in a more secure area. As for environmental factors, the population leaves hazardous places to live in attractive areas in which transport, infrastructure, and the physical environment are much more favourable.

Likewise, Bell et al. (2010) write about four types of migration in Europe, as related to labour, forced migration, international retirement, and internal migrations. They also indicate push factors such as demographic pressure, poverty, social and political hardships, and pull factors such as economic, political, and social prosperity.

Luthra, Platt, and Salamonska (2018) combine two factors of migration motivation in Europe and intended duration to hypothesise on the outcome of the migration. Identified motivation factors are economic and non-economic (experiential/educational and family) while intended duration is long term and temporary. The outcomes of the combination of these factors therefore vary between high, middle, and low economic and social integration.

There are a number of studies exploring the family dynamics during migration. The ones that show interest in patriarchy and/or masculinity during these conditions mostly focus on voluntary migrations, where people choose to leave a low esteemed place to settle in a highly esteemed area, such as a big city or a developed country. For example, Prothmann (2018) examined the migration and masculinity of young men from Senegalese rural areas to the cities for labour purposes and related challenges. Choi and Peng (2016) regarded the interplay between migration and masculinity of people leaving developing regions for developed regions for improved living conditions in China.

Likewise, Donaldson and Howson (2009) contributed to the understanding of the concept of patriarchy and masculinity as well as the struggle of men during migration. They examined how migrant men in Australia managed to keep their masculine identities within a challenging and unfamiliar context.
Patriarchy under threat during forced migration 
Innocent lyakaremye, Pudentienne Musabyimana, Jane Umutoni
The authors realised that migrant men from all over the world were more exposed than migrant women to various complications of life. They explained that this was due to men's desire to maintain power and dominance and remain providers of families, which pushed them to work very hard and longer while the new environment was less conducive. Those who did not succeed in these new ways of life, as the authors go on to explain, resorted to domestic work, traditionally known as women's work, and this challenged their capacity of decision making. The authors concluded that this shifting was very difficult and problematic.

Among the researchers who have shown interest in forced migrants, Fry (2016) focused on promoting positive male gender socialisation among Sudanese migrant male youth in Kakuma refugee camp, Kenya. Iyakaremye and Mukagatare (2016) also conducted a study on adolescent girls' sexual abuse among refugees from Democratic Republic of Congo (DRC) hosted in Kigeme refugee camp, Rwanda.

This literature reveals that patriarchy is a worldwide system rather than a peculiarity of just one country or region. It is noted that any man who is to start and maintain a family has to have a paying job, be able to manage the earned money, and be economically stable. It is also clarified that the status of man in a patriarchal context secures a number of advantages for men, including honour, respect, pride, and the feeling of responsibility of a household. This means that, even within asylum conditions, a non-providing man did not feel himself to be a real man and this might result in dangerous consequences.

With regard to all the previous literature, this paper specifically focuses on forced migration due to political unrest and insecurity for an undetermined length of time in the area of destination. This happens in the Great Lakes Region. Since the African independence era, especially in the 1960s, conflicts in this region have been causing thousands of peo-

Table 1

2015 UNHCR Sub-regional Operations Profile

\begin{tabular}{lrrr}
\hline Countries & $\begin{array}{c}\text { Refugees } \\
\text { from }\end{array}$ & $\begin{array}{c}\text { Refugees } \\
\text { to }\end{array}$ & \multicolumn{1}{c}{ IDPs } \\
\hline Burundi & 232,881 & 52,936 & 78,948 \\
DRC & 516,770 & 159,440 & $2,658,000$ \\
Kenya & 8,556 & 580,460 & 0 \\
Rwanda & 79,411 & 85,020 & 0 \\
Uganda & 7,191 & 560,170 & 0 \\
Tanzania & 857 & 296,000 & 0 \\
\hline
\end{tabular}

Source: Tunda, 2016. ple to leave their homelands and to settle abroad in search of peace and security. The reasons and sources of these conflicts are diverse. Kanyangara (2016) observes that the Great Lakes Region is "a region with interlinked conflicts and common fundamental problems that emanate from post-colonial challenges to state-building and nation-building." Concerning the causes of conflicts, he lists the "inequitable access to state, land and natural resources; a lack of equal opportunities to access political power; and the proliferation of small arms”. Shyaka (2008) links conflicts in this region with colonialism although they were not much experienced during the colonial era. For him, factors that cause these conflicts include "colonial legacy; inadequate political systems and political parties' cleavages; poor management of transitions and foreign negative interferences". He also underlines that factors causing these conflicts interfere with the peace building process.

Tunda (2016) reviews statistics of refugees fleeing from and to the Great Lakes Region countries. He realised that in 2015, there were thousands of refugees from all the countries in the region and each country had thousands of refugees from other regional countries. Using figures from the UNHCR, he illustrated the situation as in Table 1.

Table 1 shows that the high numbers of refugees were respectively from DRC, Burundi, and Rwanda. Countries hosting a high number of refugees were Kenya, Uganda, Tanzania, and DRC. The number of 85,020 refugees in Rwanda was however not negligible given the size of this country.

According to MIDIMAR (2017), in March 2017 Rwanda was hosting 128,311 refugees in the six camps of Kigeme (19,957), Mugombwa (9,041), Kiziba $(17,166)$, Gihembe $(12,416)$, Nyabiheke $(14,469)$, and Mahama (55,260). Mahama refugee camp, in which this study was conducted, was hosting $43.1 \%$ of all refugees in Rwanda; it was the newest and the largest in the country, with slightly more males (50.8\%) than females (49.2\%). This camp was established in April 2015 in the Eastern Province of Rwanda to receive Burundian refugees. The United Nations High Commissioner for Refugees (UNHCR, 2018) reports that this camp was receiving 500 refugees per month. One would thus expect that the presence of such a population within a small and highly populated country would likely be a cause of unrest.

One of the main causes of unrest is the cultural expectations of manhood among Burundians. As alluded to above, Burundian culture is highly patriarchal. This was actually the point of Basse and Kwizera (2017) in their book Norms and practices impeding gender equality in Burundian society. According to them, "Burundian society is deeply rooted in a strong patriarchal culture (...). Man incarnates authority within the household, makes crucial decisions, and provides livelihood to the members of the 
household. As for women, they are reduced to taking charge of domestic chores: farm work and house chores and caring for children and other members of the family" (p. 5).

These authors, in spite of their recent publication, may seem to take it to the extreme, as if the policy of gender equality that is currently upheld by the international community and countries had not yet started influencing the mindset of the $\mathrm{Bu}$ rundian community. These authors go on to underline the Burundian man's position of authority and woman's position of subordinate as illustrated in the proverb "Nta nkokokazi ibika isake ihari" (The hen never crows when the rooster is around), meaning that whenever the man is present, he is the only one to command, not the woman. They also highlight that women are always oppressed whenever the family's expectations are not achieved, such as in the case of barrenness, as well as the culturally justified oppression of women in many settings from the innumerable household and farming duties to physical and psychological violence. Impunity Watch (2017) and Falch (2010) instead focus on women's exclusion from the public arena in Burundi. They explain how women were not consulted or given due consideration in political leadership and in peace negotiations. For these authors, the inclusion of women was always informal and unofficial. According to Impunity Watch (2017), "Female interviewees across the political spectrum agreed that their participation in peace negotiations in the context of the current crisis remains ad hoc. Not only are they not systematically invited to sessions of the negotiations, but they have to lobby mediators fiercely even for their inclusion. (...) Women's right to political participation, and the sensitivity for inclusive gender negotiations, is still poor, regardless of whether the focus is the government or political parties" (p. 4).

All these authors however agree on the point that until recently, Burundian men were in charge of everything and were custodians of all important decisions in public and in the family sphere. Do these cultural standards remain unchanged within refugee camps? The overall observation in all this research is that it timidly focuses on the influence of forced migration on patriarchal structure and the management of masculinity within couples, families and households. Trying to fill this gap, this study focuses on the family structure and management, relationship, and gender role division. More specifically, attention in this study is drawn to the management of masculinity within patriarchal culture by men dwelling within conditions that, to a certain extent, betray the exercise of their cultural standards of manhood, within the refugee camp where all people depend, not on men as such, but on the UNHCR and international organisations.

\section{PARTICIPANTS AND PROCEDURE}

The study was conducted during two weeks in October 2018, among Burundian men in Mahama refugee camp located in Eastern Province, Rwanda. It was designed as a qualitative study and used qualitative approaches in data collection and analysis. The study involved twenty-one men who were systematically and purposively selected for individual interviews and focus group discussions (FGD) respectively. Of these, ten were interviewed individually and 11 approached in one FGD. Five key informants from Mahama refugee camp also contributed to this study.

The list of families and the camp's map were used in the selection of participants in individual interviews. This list had information on the gender and marital status of family members. The camp had five zones and the researchers' target was two men per zone, with consideration of cardinal points. In the first zone, participants were randomly chosen in the middle. In the second zone, they were chosen in the northern part. In the third zone, the choice was made in the south. In the fourth and fifth zones, participants were respectively selected in eastern and western parts of the zone. In each zone, interviews were only conducted with men who were already married when they left Burundi to seek asylum in Rwanda.

FGD members were selected at the central food distribution site that was used by large families. One volunteer camp staff who was familiar with them helped in selecting men aged thirty years and above who were already married when they left their country in order to settle in Rwanda. Initially, the target for FGD was ten men. But after their selection, one man who fulfilled the selection criteria voluntarily joined the group and was accommodated.

Data were collected using semi-structured interview and FGD guides. Individual interview and FGD guides had the same content pertaining to four themes: financial and living conditions, resources and management within the camp; family relationships, the problem of intimate partner violence (IPV); and psychosocial issues related to the frustration of being forced to live outside their own context.

Interviews were conducted in relatively comfortable places jointly selected by the interviewer and the interviewee. For individual interviews, people were sitting either inside the house or outside where they could ensure the confidentiality or could see from a far anyone who attempted to come closer to them. In such cases, they would notify them of their need of discretion in order to avoid disturbance. Likewise, the FGD was conducted while sitting in the grass outside the house, at about 50 meters, a place not utilised by other people in the camp. As for key informants, they chose to be interviewed within their working offices.
Patriarchy under threat during forced migration 
During data collection, no major issues occurred that could disturb the activities or the findings of the study. Only the choice of the right place for interview sessions took some minutes because of the high density of the population in the camp. There was an advantage of Kirundi language spoken by Burundians, which is very similar to Kinyarwanda spoken by Rwandans, which facilitated the data collection. Data collection activities were conducted by two experienced women. Because of their experience in working and conducting studies with both men and women in the community, they did not have any constraint linked with their gender. The findings of this study give account of what Burundian men are experiencing in Mahama refugee camp in terms of exercising their power and position as in patriarchal culture.

\section{FINDINGS AND DISCUSSION}

This section presents and discusses the results of the study. It elaborates on the (in)consistency of patriarchal family structure and gender role division during forced migration, the influence of family structural dynamics on the couples' power sharing and relations, and the coping mechanism developed by men in reaction to the new structural setting of the family. The conclusion wraps up with a summary of findings, limitations and suggestions for future research.

\section{INCONSISTENCY OF PATRIARCHAL FAMILY STRUCTURE AND GENDER ROLE DIVISION DURING FORCED MIGRATION}

The findings of the study reveal that there is inconsistency of the family's structure and gender role division during forced migration. Changes are observed in various areas:

The number of people in the household. It was noted among more than half of participants that the number of household members who left their original home to go to Mahama refugee camp had changed, either increasing or decreasing. The increase of the size of the households was for example caused by new babies born along the way and people who joined the family group during fleeing circumstances. The decrease could be due to people separating from each other during displacement and some cases of death. Some young people had also left their family circle to form their own couples, but all the new couples were just cohabiting, thus not getting legally married, because conditions of organising proper ceremonies for these rituals were not easy to fulfil.

Change of men's professions. Men who participated in the study disclosed that before leaving their home country they had various professions from a high level to a low level. However, only one man, who was a builder, among all men who participated in the study could find some occasional opportunities to do some jobs, while other men were just there without a visible occupation. Some men with a high education level of qualification had decided to take up voluntary jobs within humanitarian organisations as a way to avoid remaining at home and performing unpaid household activities that are initially reserved for women.

Donaldson and Howson (2009) had observed the same scene among the migrant men in Australia as mentioned above in the introduction. They found their skills looked down upon and could not secure a job that would match their highest qualification. They accepted undervalued positions just for survival but they invested much in their children, who would have accepted qualifications at the completion of their studies.

Household equipment. Most of the refugees were not in possession of household equipment as it was in their home country, such as television sets, radio sets, telephones, bedding, tables and chairs, cars and bicycles. The man in FGD (No. 7, 58 years old) said during individual interview, "In my home country, I had a good house well equipped with a television set and everything but now I do not have even a simple telephone". The man in FGD (No. 9, 43 years old) said, "It was a security issue. We could not take a heavy television set or chairs with us as we had to run away for a long distance and hide ourselves. I was only able to put my small radio set in the jacket pocket. My car was left at home".

This loss of equipment happened because it was difficult to transport such equipment during forced displacement. Other equipment was sold in order to have money to buy food for survival on their way to the host country.

Family hierarchy. As indicated earlier, according to Burundian culture, men are the ones heading families. This is a position held by the powerful person who is the breadwinner, able to provide for the family, who has the last word in decision-making on what happens in the household. In the refugee camp, this patriarchal culture was no longer strictly respected. Women were the ones who mostly had these possibilities and qualities. One of the reasons is that women and children were the ones who first arrived and installed themselves in the camps. Women were therefore declared heads of families because men were not yet around. Women were given the capacity to stand on behalf of the whole family and were handed the card that is used at the UNHCR counter in order to obtain the food and other support for subsistence on behalf of the whole family. When men came later, the name of the head of the family did not change in the records of the UNHCR. Women remained representatives of families in spite 
of Burundian patriarchal culture as described above. This new structure gave women the capacity to be the ones who decide on the use of subsistence allowances and on the subsistence of the household, and to sell or buy various items where necessary.

Thus men were not recognised in the records of the UNHCR as representing their families. They were recognised as family members represented by women at the same level as children. Some men in the focus group discussion observed that even for men who still feel that they are heads of families, they are so by name, not by fact.

Gendered roles in the household. In Burundian culture, a man is the provider of the family. He has to have money and to supply his family with all they need. The man has to protect the family, and to ensure physical and food security. For this reason, a man had to work hard in order to keep the family safe. But they do not have that capacity in the refugee camp. Some of them remain idle in the camp. Very few go outside the camp to find some odd jobs. Others opted for domestic chores. They take care of babies and young children, feeding and washing them as well as clothing them. They wash clothes or prepare food for the family. They clean the houses, fetch water or accompany their wives at the UNHCR point of food distribution in order to transport them to their house.

Although this transformation in terms of gender roles may be seen as positive by proponents of gender equality, Burundian men expressed that they are not happy with it. They feel like they have no value and are useless. In this regard, man No. 3 (49 years old) in an FGD complained, in agreement with other group members, that, "Nowadays here in the camp, things have changed a lot and we are asking ourselves if we are still real Burundian men. Look, here the living style is very different from the one we used to see: for example, as men we cannot say that we are all still the main providers of our family because all of us depend on the ADRA ${ }^{1}$ to get food and other non-food items like our wives and children do. And the problem is that our children and wives do not understand that things have changed and continue to stress us in asking for different things that we do not have".

This excerpt shows that patriarchal inequality is engraved in men's, women's and children's ways of life. This is because while men are complaining that they are no longer able to provide for their families, their wives and children also still expect these men to provide for them and judge them on this basis. Thus, people in Mahama refugee camp are visibly living a different life as compared to their expectations as per the life in Burundi.

Likewise, women in Burundian culture are expected to perform domestic chores such as cooking, washing and clothing children, cleaning the house, and fetching water and firewood. Burundian women were also expected to cultivate the fields. Some women in the refugee camp are still performing domestic chores. But others are playing the role that was initially assigned to men such as working for money within and outside the camp in order to supplement the subsistence allowances that they receive from the UNHCR. Some have a monthly income from paid work in humanitarian organisations. They are now breadwinners and they provide for the family. In this regard, a man in an FGD (No. 10, 44 years old) commented during an individual interview, "We are also realizing that some women do the hard jobs like working at a construction site and when we were in Burundi you could not find a woman on a roof constructing a house working together with men. Here things have changed and our culture has lost its meaning".

This means that gender roles no longer apply in Mahama refugee camp; men and women carry out all sorts of activities although men view it as strange.

Financial earning. The roles played in the community or in any institution determine the access to resources and financial status. Life in the camp does not offer more opportunities to earn money. People mostly depend on the subsistence allowances provided by the international community through the UNHCR and international organisations. Sometimes these subsistence allowances are sold in order to have money for other needs. There are a few refugees who go outside the camp to work for money in the neighbours' fields and other odd jobs. Others sell some items within the camp such as biscuits, sweets, and agricultural products. Some refugees also make and sell small handicraft items. Other people volunteer in organisations' activities and receive a token payment of 600 Rwandan francs (\$0.67) per day. There are others who are trained in savings activities, and thus can save people's money or give small loans with a small amount of interest.

Men are the ones who used to have odd jobs in the neighbouring community. But many women are privileged through being registered as family representatives, possessing the card ("proof of registration") which is used to collect food and other allowances for the family. This status offers them access and capacity to use the allowances that they receive with the possibility to sell some of them and get money. In addition, within families, women are normally younger than their husbands, and thus relatively physically stronger than them, which also is an advantage for them in terms of being able to work for money. International organisations that can offer jobs or voluntary work also prefer women as part of enforcing the Rwandan policy of promoting gender equality and women empowerment.

In addition to all these ways of earning money, the other concern is in its use. While women bring all they earn in order to sustain the family, men
Patriarchy under threat during forced migration 
Innocent lyakaremye, Pudentienne Musabyimana, Jane Umutoni spend most of what they earn on alcohol. Man No. 8 (52 years old) stated during the FGD, "This is a little bit strange here in the camp although it depends on families. Without lying in most cases here in Mahama camp, women gain more than others because it is easy for them to find a job, many organizations uphold them saying that they are more vulnerable than us [men]. (...) The big difference is that where the women gain more the whole family enjoys the income that is used at home but where men earn much money they use it to consume a big amount alone with their male colleagues taking alcohol while only a small amount of income reaches the rest of the family members".

This situation therefore places women in a higher position in regard to money earning, which is not a common occurrence in Burundian society.

The changes observed in this study are similar to those observed in Ireland by Page (1999), although in another setting of unemployment rather than refugee life. When women improve their financial status, the role they play in the household and the community changes as well, with a tendency to attain more freedom, to provide for the family, and to enter the public arena. A quote of one respondent in Page's study reads as follows, "When a man went to work he gave the wife money for the house, now it's gone to the other extent, where the women are going out and keeping the house going till the men get jobs. That men providing things doesn't work anymore, there was this wonderful attitude that men, not all of them mind you, but most men treated their wives severely and said 'I'm the boss'. It's the other way round now, an awful lot of men can't cope with that. They think it's a terrible, demeaning thing" (pp. 50-51).

What is common in these Burundian and Irish men is that they are surprised and sometimes feel uncomfortable of these changes in women's economic capacity. What is now the impact of all these realities in Mahama refugee camp that seem to challenge the Burundian community structure where only men are dominant? Does it occur without conflict in the life of the family?

\section{INFLUENCE OF FAMILY STRUCTURE DYNAMICS ON THE COUPLES' POWER SHARING AND RELATIONS}

The changes in structure and hierarchy within migrant families affect the family relations and the hierarchy of powers. Aspects of family power relations that were affected are the following.

The power to decide on the use of money. Because women are more involved in earning money than men, still women are the ones that have much to say about the use of this money. However, women always decide on the money that they have earned, not the money earned by the husband. Man No. 6 ( 57 years old) in the FGD stated, "When we were in Burundi, things were really easy. Women were polite and us men were the bosses in the households. We were governing all important wealth. The serious decisions around the money were taken by husbands and then we [men] were deciding about its use; the money was managed under our responsibility. We even held power over the money earned by our wives. But here, we do not know what happened to us because women have said that they have full power to decide on their money and we no longer have any decision over them".

Man No. 10 (36 years old) in the same group discussion also mentioned, "Here in the camp the decision on earned money is personal. If it is the money of the woman, she manages it as she wants and when the husband has his own money he has the full choice to use it as it pleases him".

Having a woman deciding on the use of money is very different from what was happening in Burundi, where a man would control the use of all financial wealth, even when he was not the one who earned it.

Communication among family members. Participants stated that communication in the family was no longer healthy. In the camp, individualism tends to replace the togetherness of the households and the family. Couples have reduced mutual consultations. Each member of a couple is working on their own without necessarily informing the partner. Because of the financial imbalance between wives and husbands, with the man being less privileged, men no longer feel happy to exchange with their wives in a friendly manner. They therefore become "others" and sometimes enemies to their partners. Rather than being closer to their partners, some men resort to walking away to join other men in alcohol and they come back late when it is no longer a convenient time to have sustained talk. In elaborating on this point, one group participant (No. 5, 41 years old) said, "Yes, it is understandable that you cannot communicate with your partner in the same way as other people. But when we are in conflict we communicate in a negative way and sometimes we decide to keep quiet in order to avoid additional problems". Man No. 2 (47 years old) also mentioned during the FGD that, "When we have problems at home we choose to go to see our colleagues and we share with them instead of discussing with our wives in order to avoid beating our wives and children". This was not the case when they were still in their home in Burundi, where men were breadwinners and women could be submissive.

Men's internal security. Men's self-actualisation was no longer nourished. They seemed to have lost hope of being "men" any more as expected in their cultural context. They were no longer productive. They found themselves performing activities that were initially assigned to women such as cooking, 
caring for children, washing clothes, etc. Some women also took advantage of men's critical situation to look down on them and to humiliate them. The following excerpts express men's frustrations:

"In general, women are very happy to carry out men's tasks because some of them provide to them honour to feel superior to men. The problem is that when we provide many things at home women admire us but when we do not have anything they disrespect us" (FGD No. 1, 51 years old).

"Here in the camp, things have changed against men because we, men, are progressively losing our power and the situation here in the camp leads us to do what is not acceptable by our Burundian culture. To find a man washing dishes and cleaning the house and other household activities is not seen as normal and we feel frustrated and humiliated" (FGD No. 7, 62 years old).

"Our wives are favoured by the system here in the camp because they have different occupations in the camp and sometimes they abuse this favour, they lose the sense of respect towards their husbands" (FGD No. 4, 38 years old).

"When your wife does not respect you as husband, children automatically do not respect you and finally both we and our wives risk losing respect from our children. This pushes some children to leave the household in order to live with their peers and to misbehave. For example, our daughter got pregnant because of family conflicts" (FGD No. 9, 69 years old).

"The main cause is that we are not still the main provider of households. We have lost our real power to have the last say on what happens at home. We do not have enough income, and the assistance received from humanitarian organizations is well calculated depending on the family size and we cannot use it for buying other needed items. When we ask our wives to allow us to have even one bottle of beer so that we can forget our problems they do not understand us, they rather quickly go to the MIDIMAR ${ }^{2}$ and UNHCR to lodge their complaint that we are mismanaging the received assistance" (FGD No. 6, 57 years old).

"No, how can men decide in everything when they are no longer the main family providers? It is not possible even if your wife does not tell you that you are no longer the head of the family, you yourself have this feeling of low self-esteem and you feel you are not a real and good man. You try to cope but this complex of inferiority remains within you" (FGD No. 3, 49 years old).

These excerpts highlight that men in Mahama refugee camp felt frustrated and insecure as a result of changes in couples' power sharing and relations. Men's frustrations and tensions of this kind are potentially very dangerous and, as alluded to in these excerpts, reactions can be directed towards not only women, but also the children and the staff in charge of the camp management.
Similar to Page's study (Page, 1999) in Ireland, the higher women grow in power, the lower men feel in power. It is like men had women's power, and when women get power, they withdraw their own power that men had owned, then men's power becomes less. A respondent in Page's study said, "It was like I had her power and when she was going forward she was taking back that power. She wasn't robbing mine, just taking back her own power and that was scary for me, I couldn't focus. All my energy was going into her moving on, it showed me how insecure I was" (p. 53).

The frustration is therefore real among men when they find that women who were initially dependent on them are now self-reliant.

Intimate relationships of the couples. Because of the unhappy living conditions, mutual love within some couples had notably decreased. The collaboration between couples was not always assured. Friendly advice was rare, and intimate relationships were not as healthy as before. Men complained that they were no longer considered by their wives as real men. Since the UNHCR and international organisations were the main providers of refugee families, these were considered as "actual men" and "actual husbands". Some cases of women's addiction to alcohol and adultery with wealthier men were also involved.

Some men's complaints about this matter during group discussion are as follows:

"In Burundi, we used to have sex with our wives as much as we wanted, but here in the camp things have changed and they refuse, saying that the children can hear us but when we observe their attitude it is like they do not want it because we no longer provide anything at home" (No. 10, 36 years old).

"If your wife rejects sexual intercourse with you, this means that there are some other men who are doing it with her, men who may even be younger than you or have much money while you do not have anything" (No. 7, 62 years old).

"When we communicate negatively, our intimate relationship is affected in different manners, we cannot plan together our household future and the management of family property. Even our intimate relationship does not function well when we have misunderstandings" (problems of sexual satisfaction among different couples) (No. 4, 38 years old).

"Life has changed and the whole situation has changed. Imagine a woman who dares to tell you that you are not a man, that the UNHCR and MIDIMAR are better than you. Or a woman continues to ask you what she used to have in Burundi while she really sees that you do not have them" (No. 1, 51 years old).

"The fact of being productive in the family while we all depend on international aid, some women leave us and join wealthier and stronger ones" (No. 10, 36 years old).

These men's voices express a kind of disunity and tiredness of couples in their intimate relation-
Patriarchy under threat during forced migration 
Innocent lyakaremye, Pudentienne Musabyimana, Jane Umutoni ship. Because of these challenges, some couples find themselves even fighting without real reasons, for example because the pots are not in their place, because someone is standing before the other, because the child is not washed, etc. Still, men do not have the right to be harsh to their wives. When they try, they are punished by the camp management.

Women's submission and respect to men. As men complain, the fact of being considered by their wives as useless and inferior because they are no longer productive dictates the respect and honour they are given. Since women were the ones possessing the "proof of registration" (card used during the distribution of subsistence allowances), they were leaders and chiefs. Women had become heads of families, replacing men in that role. In terms of hierarchy, men were repositioned at the level of children in the family. Nine men out of eleven that were in the group discussion confessed not being able to decide on anything in their household. When they are disrespected by their wives, children follow their mother's example. Men accused women of having made themselves men while they were women (ibishegabo), which means that women were fighting to be the ones respected and honoured.

Man No. 6 (36 years old) in an individual interview was disturbed that his wife was exemplary in respecting him when they were still back in Burundi and that in the refugee camp she was no longer submissive. He explained that although she became born-again in Rwanda, her behaviour changed for the worse to the point that she was insulting him in public. Other men shared the same opinion as follows, "Before coming here in the camp, our wives were shy and respected us very much; once in the camp, many of them changed in their attitudes. They are not even ashamed to insult their husbands in public. Maybe it is because they now have means [money] and power given by the camp's authorities which lead them to feel superior to us. Many of them are working and earn money; that is why they have become alcohol consumers and they cannot listen to their husbands" (Individual interview No. 10, 44 years old).

"In the camp, our culture is facing different deviations. Women have open eyes and when you observe here in the camp, women seem to be more empowered than others. Maybe it is because here in Rwanda women have been put in front and ours started to imitate Rwandan women. They find jobs more easily compared to us, and some of them have become the main providers of households. This change of women's status does not help us at all. Such women do not respect their husbands and sometimes humiliate them in public, saying that they [women] are living on their own means" (Individual interview No. 2, 45 years old).

"In general, women are very happy to carry out those mentioned tasks because some of these jobs provide them honour to feel superior to men. The problem is that when we [men] provide many things at home women admire us, but when we do not have anything they disrespect us. But when they are the ones who have means, they start to blame us, accusing us that we are not important to them and complain that we are at home just to take advantage of what they have gained from their own effort, just to suck them" (FGD No. 1, 51 years old).

It seems therefore that the relationship of domination and submission within couples was also affected by the life in the camp. What can be observed here is the collusion of Rwandan and Burundian cultures. Although these countries have almost the same history and the mobility of their population in either country is intense, Rwanda has recently shown a higher level of gender equality promotion and women's empowerment. This advancement therefore may have reached a level of women's emancipation that was looked at by Burundian men as cultural deviation.

In Australia, Donaldson and Howson (2009) also found that migrant men were highly frustrated by the inability to provide. They observed that this inability caused them the loss of respect, dignity, power and authority, to the point that they compared a non-working person to a dead person. They also complained that the system was only favourable to women, which they considered as bias.

As to the change in couples' power relationship resulting from women's empowerment and change in traditional gender role division, Page (1999)'s male participant in Ireland realised that women who grow higher and higher are no longer controllable by the male partner. Speaking of the situation in his own couple, he explained, "She started to grow, I wanted us to work together, but I had an agenda. I wanted her to go forward but I wanted to her to go my way and that's not what happened. We started to go forward all right but in different ways. She started getting her own space and became strong and confident in herself. (...) Previously I had control of the situation, so I had part of her if you know what I mean. Here all of a sudden was little old me, fucking left behind, she went from strength to strength. The idea was that the two of us would grow together but I still wanted control and I couldn't do it that way" (p. 52).

What is expressed here is men's resistance to changes of men-women relationship within the patriarchal setting. This happened in Rwanda as well during the course of gender equality promotion and enforcement of national gender policy where some men interpreted it as if Rwandan President Kagame has allowed women to disrespect men. In the same way, both Burundian men living in Mahama refugee camp and Irish men thought that women had taken their rights and privileges too far. In reaction to all these surprising attitudes and behaviours of women in the refugee camp, Burundian men have developed strategies in order to cope with the new settings. 


\section{MEN'S COPING MECHANISM IN REACTION TO THE NEW STRUCTURAL SETTING OF THE FAMILY}

Men who have faced challenges in their homes have developed a number of strategies in order to cope with life. Five of these strategies are however prominent.

Cooling down and keeping silent until their anger and that of their wives has subsided. This is a very difficult exercise since a real man in Burundian culture has to be a brave and strong person who is responsible and the controller of the whole family.

Seeking separate registration. Some men sought to be removed from the wife's proof of registration in order to request their own document as a single person. This separation at least gave men the possibility to obtain some food that they could manage without the control of their wife. This kind of separation was however dangerous since it risked transforming into a real physical separation from the wife and the beginning of all kinds of immoral behaviour. In addition, this affected the social and formal education of children, who saw their parents in the same camp but could not stay together.

Leaving their house to settle in the surrounding community. Some men just left their house for a while and went to the surrounding communities to stay there for some days up to two or three weeks. Then they came back when they and their wives were no longer angry or when they had felt a need for each other. Meanwhile, the man could do some odd jobs in the surrounding community and come back with some money. This situation was however another open door for cheating and adultery for the man who went outside and for the woman who was left alone in the camp.

Leaving their home for hours. Other men left their homes for hours, rather than days or weeks. They walked around until they felt that they could come back home and stay together with their wives. Outside there they could pay a visit to a friend or share a bottle of beer with friends. This was another way to unfaithfulness since while they were still angry against their wives, they could find other women who were more comforting and could try to develop relationships with them. Another risk here was alcoholism and drug abuse while thinking that they were looking for calmness and peace of mind.

Cohabiting with other women. Some frustrated men chose to cohabitate with other women after separation of proof of registration. Key informants mentioned this issue, indicating that they used to receive complaints that men separated in order to join their girlfriends. This coping strategy was a threat not only to the former household but also to the security of the community in the whole camp because it raised a lot of conflicts, rivalry, and jealousy.

Some of the men who experienced wives' refusal to have access to the subsistence allowances from the
UNHCR tried to obtain them forcibly, which caused conflicts, and such cases were reported to those in charge of security in the camp.

The other coping mechanism developed by frustrated men was physical abuse. They abused their wives physically in slapping or punching them or using any other means to hit them. Abused women might take the case to the security officers of the camp or they could just separate from the husbands within the same house. There were women who, because of the abuse, left the couple's bed to sleep together with children in children's beds.

Some men thought that all these abusive reactions of the men were their rights, and that women were the ones to be held accountable. They argued that men should be the ones in possession of wealth, not women, and that otherwise women would always abuse this superiority. Man No. 6 (36 years old) in an individual interview mentioned: "Yes, in general when women gain more income, the family enters into conflict because men ask them to give money and they refuse; but where the husband is the main provider, there is no problem, because they respect each other. These troubles happen because when a woman has much money she thinks that she has become superior to her husband and consequently children respect their mother rather than their father because they consider their mother as the boss since she provides to them all they need".

This man thinks that it is the right of the man to be the only one who decides on all income of the family, even income he did not earn. Such mentality is an expression of the low level of understanding of the principles of gender equality. This means that this refugee community needs to be educated to have the minimum understanding of gender equality for both women and men, and to protect the family as an institution.

\section{CONCLUSIONS}

It is known that women are the most affected by forced migration due to risks and cases of sexual and gender-based violence. This paper however brings an unfamiliar analysis where men are suffering and women have room to enjoy in spite of having to play more roles for the family. This study sought to explore how forced migration affects patriarchal structure and bonding among couples and to suggest strategies to address subsequent challenges while promoting gender justice and protection of the family institution.

The results showed some inconsistencies of patriarchal family structure and gender role division. Changes were observed in size of the family, professional enjoyment, commodity possession, family hierarchy, gendered role division, financial earning, and financial management. Along with these changes,
Patriarchy under threat during forced migration 
Innocent lyakaremye, Pudentienne Musabyimana, Jane Umutoni men seemed to be losing what the patriarchal cultural norms had guaranteed them to the benefit of women.

These changes in family structure led to changes in men's and women's power sharing and relationship. These included the change of power to decide on the use of money, communication among family members, men's attitude and internal security, intimate relationships within the couples, and couples' mutual respect.

In the face of all these changes, men developed mechanisms to cope with the new settings. They might cool down in order to create and keep a good atmosphere in family relations or separate family registration as a way to seek freedom. Men might temporarily walk out on their wives or cohabitate with concubines.

The intention to write this paper was neither to complain together with Burundian men about their suffering in refugee camps nor to accuse them nor to rejoice over the unexpected experience they are having. It was rather meant to show what was happening in the refugee camp and the transition through which these men were passing so that competent authorities can be aware of the dynamics of the population they have. That could help them plan to work with them accordingly in order to avoid any negative consequences likely to occur while respecting their dignity and rights. It is therefore argued here that men also have rights to be supported in such a transitional phase as is often done for women and children in emergency settings.

As alluded to in some statements of interviewees, what was perceived in this paper as change favouring women might have been influenced by the Rwandan policy of promoting gender equality and women empowerment and its reputed seriousness in implementing it. The findings of this study cannot claim to give a full picture of the family dynamics among all refugees. Further research could be conducted among refugees from other cultural perspectives for comparison.

\section{ENDNOTES}

1 The Adventist Development and Relief Agency 2 Ministry of Disaster Management and Refugee Affairs

\section{References}

AP Human Geography (n.d.). AP Human Geography Outline. Retrieved from http://www.sps 186. org/downloads/basic/430069/APHG\%20Notes.pdf [accessed May 6, 2019].

Asiyanbola, A. R. (2005). Patriarchy, male dominance, the role and women empowerment in Nigeria.
International Union for the Scientific Study of Population (IUSSP/UIESP) XXV International Population Conference Tours (pp. 18-23). France.

Basse, Y. O., \& Kwizera, J. (2017). Norms and practices impeding gender equality in Burundian society. Dakar: Care International.

Bell, S., Alves, S., Silveirinha de Oliveira, E., \& Zuin, A. (2010). Migration and land use change in Europe: A review. Living Reviews in Landscape Research, 4, 1-49. Retrieved from www.livingreviews.org/lrlr2010

Bhugra, D., \& Becker, M. (2005). Migration, cultural bereavement and cultural identity. World Psychiatry, 4, 18-24.

Choi, S. Y., \& Peng, Y. (2016). Masculine compromise: Migration, family, and gender in China. California: University of California Press.

Del Aguila, V. E. (2014). Being a man in transnational world. The masculinity and sexuality of migration. New York: Routledge.

Donaldson, M., \& Howson, R. (2009). Men, migration and hegemonic masculinity. In M. Donaldson, R. Hibbins, R. Howson, \& B. Pease (Eds.), Migrant men: Critical studies of masculinities and the migration experience (pp. 210-217). New York: Routledge.

Falch, A. (2010). Women's political participation and influence in post-conflict Burundi and Nepal. Oslo: Peace Research Institute Oslo (PRIO).

Fry, W. M. (2016). Promoting positive male gender socialization among migrant male youth living in $\mathrm{Ka}-$ kuma refugee camp, Kenya: Applying appreciative inquiry to gender-based violence prevention efforts. $\mathrm{PhD}$ in public health dissertation. Chapel Hill: University of North Carolina, Gillings School of Global Public Health.

Impunity Watch (2017). Policy brief. Masculinities, violence against women in leadership \& participation in transitional societies: Burundi \& Guatemala. Enhancing UNSCR1325 implementation. Syracuse, NY: Syracuse University.

Iyakaremye, I., \& Mukagatare, C. (2016). Forced migration and sexual abuse: Experience of Congolese adolescent girls in Kigeme refugee camp, Rwanda. Health Psychology Report, 4, 261-271. https://doi. org/10.5114/hpr.2016.59590

Kambarami, M. (2006). Femininity, sexuality and culture: patriarchy and female subordination in Zimbabwe. South Africa: Africa Regional Sexuality Resource Centre.

Kanyangara, P. (2016). Conflict in Great Lakes Region. Root causes, dynamics and effects. African Centre for the Constructive Resolution of Disputes (ACCORD). Retrieved from www.accord.org.za/conflict-trends/ conflict-great-lakes-region/ [accessed September 20, 2018].

Luthra, R., Platt, L., \& Salamonska, J. (2018). Types of migration: The motivations, composition, and early integration patterns of "new migrants" in Europe. 
International Migration Review, 52, 368-406. https:// doi.org/ 10.1111/imre.12293

MIDIMAR (2017). Protection and assistance to refugees (Pamphlet). Kigali: Ministry of Disaster Management and Refugees. Retrieved from www.midimar. gov.rw/fileadmin/templates/css/PROTECTION_ AND_ASSISTANCE_TO_REFUGEES_PROJECT. pdf [accessed January 29, 2019].

Nyirahabimana, S. (2015). Effectiveness of divorce prevention mechanisms in Rwanda: assessment of court conciliation, family and umugoroba w'ababyeyi in Gasabo district. Kigali: University of Rwanda, Centre for Gender Studies.

Page, P. (1999). Masculinity in crisis? A study on the threat to masculinity identities through unemployment. Master thesis. National University of Ireland, Maynooth.

Prothmann, S. (2018). Migration, masculinity and social class: Insights from Pikine, Senegal. International Migration, 56, 96-108. https://doi.org/10.1111/ imig. 12385

Republic of Rwanda (2016a). Law governing persons and family No. 32/2016 of 28/08/2016. Official Gazette No. 37 of 12/09/2016.

Republic of Rwanda (2016b). Rwanda demographic and health survey 2014-2015: Final report. Retrieved from https://dhsprogram.com/pubs/pdf/FR316/FR316.pdf

Shyaka, A. (2008). Understanding the conflicts in the Great Lakes Region: An overview. Journal of African Conflicts and Peace Studies, 1, 5-12. https://doi. org/10.5038/2325-484X.1.1.1

Strijdom, G. H., Luttig, L. E., Ferreira, G. V., Kellerman, A. P., \& Swart, H. (1997). The family and divorce. Marriage and family life in South Africa: Research priorities. Pretoria: HSRC.

Sultana, A. (2011). Patriarchy and women's subordination: A theoretical analysis. Arts Faculty Journal, 4, 1-18. https://doi.org/10.3329/afj.v4i0.12929

Tunda, K. F. (2016). Refugees in Great Lakes Region. Retrieved from www.accord.org.za/conflict-trends/ refugees-great-lakes-region/ [accessed September 30, 2018].

Umoh, S. H., \& Adeyemi, H. (1990). Causes of divorce as perceived by students of tertiary institutions in Kwara State. Retrieved from www.unilorin.edu.ng/ journals/education/ije/dec1990/CAUSES

UNHCR (2018). Sustaining results. A 9-month postdeployment impact assessment of the Senior Protection Officer (SGBV) in Mahama camp, Rwanda. Kigali: The UN Refugee Agency (UNHCR). 